Correction

\title{
Correction: Trua, T.; Marani, M.P. Clinopyroxene Crystals in Basic Lavas of the Marsili Volcano Chronicle Early Magmatic Stages in a Back-Arc Transcrustal Mush System. Geosciences 2021, 11, 159
}

\author{
Teresa Trua $^{1}$ (D) and Michael P. Marani ${ }^{2, *(D)}$ \\ 1 Dipartimento di Scienze Chimiche, della Vita e della Sostenibilità Ambientale, Università di Parma, \\ Campus Universitario_Parco Area delle Scienze 157A, 43124 Parma, Italy; teresa.trua@unipr.it \\ 2 ISMAR-CNR, Istituto di Scienze Marine, Consiglio Nazionale delle Ricerche, Via Gobetti 101, \\ 40129 Bologna, Italy \\ * Correspondence: michael.marani@cnr.it
}

check for updates

Citation: Trua, T.; Marani, M.P. Correction: Trua, T.; Marani, M.P. Clinopyroxene Crystals in Basic Lavas of the Marsili Volcano Chronicle Early Magmatic Stages in a Back-Arc Transcrustal Mush System. Geosciences 2021, 11, 159. Geosciences 2021, 11, 406. https://doi.org/ 10.3390/geosciences11100406

Received: 15 June 2021

Accepted: 14 September 2021 Published: 27 September 2021

Publisher's Note: MDPI stays neutral with regard to jurisdictional claims in published maps and institutional affiliations.

Copyright: (c) 2021 by the authors. Licensee MDPI, Basel, Switzerland. This article is an open access article distributed under the terms and conditions of the Creative Commons Attribution (CC BY) license (https:// creativecommons.org/licenses/by/ $4.0 /)$.
The authors would like to make the following corrections to this paper [1]:

In the original article, the captions of Figures $2-4$ are not matched with the figures. The caption of Figure 2 was wrongly used for Figure 3, the caption of Figure 3 was wrongly used for Figure 4, and the caption of Figure 4 was wrongly used for Figure 2. The correct captions with the figures appear below.

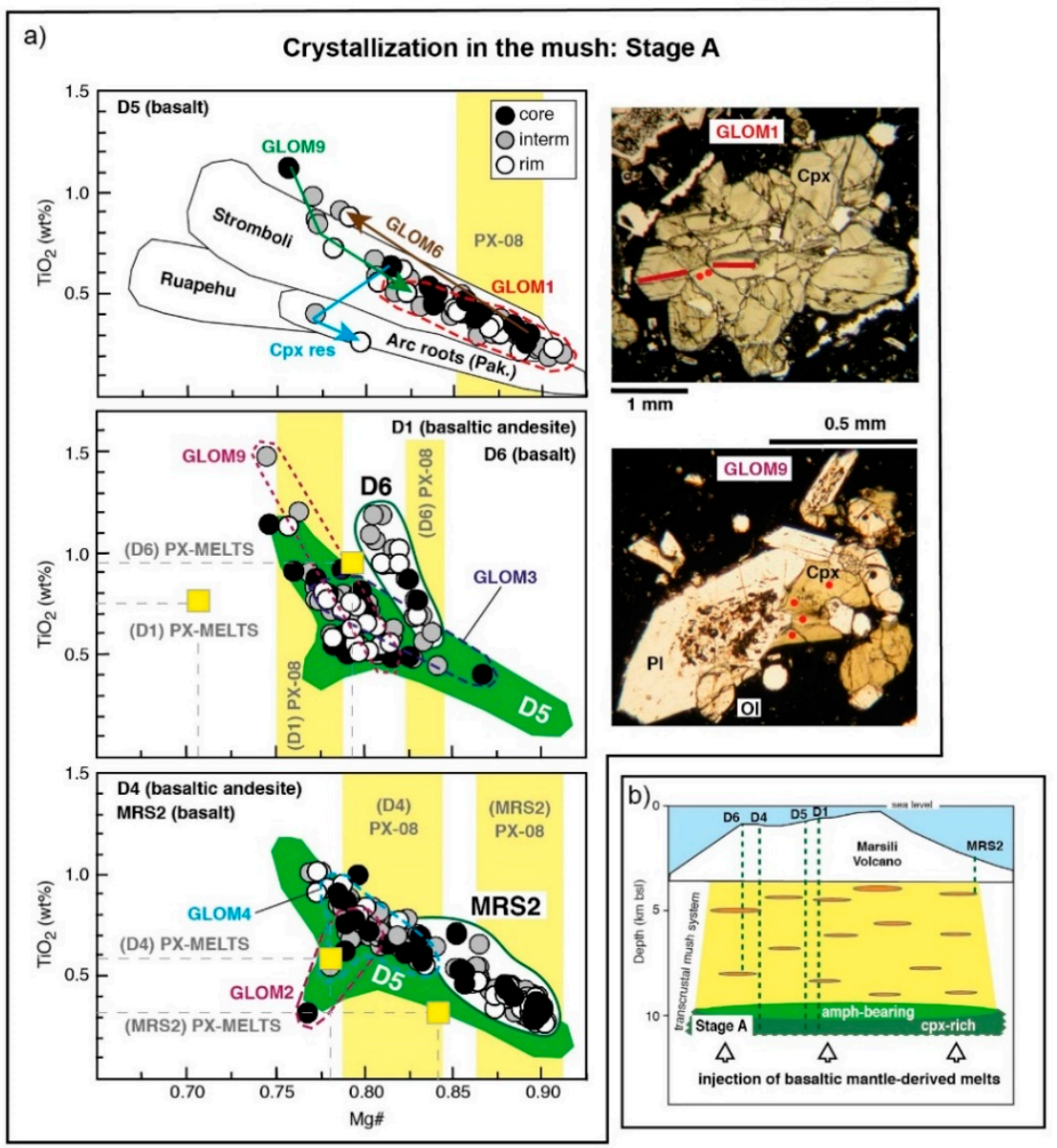

Figure 2. Clinopyroxene variability indicative of Stage A crystallization. (a) $\mathrm{TiO}_{2}$ (wt $\%$ ) versus $\mathrm{Mg \#}$ 
for the clinopyroxene crystals in basalts to basaltic andesite lavas, top to bottom: D5; D1 and D6; MRS2 and D4. Estimated analytical error (2 standard deviation) was smaller than symbol size. The yellow box and the yellow vertical band refer to the Mg\# equilibrium values indicated by the PX-MELTS [18] and the PX-08 (this study) results, respectively. Analyses of selected crystals (single or in glomerocrysts) are indicated with their abbreviation (see Supplementary Tables S2-S13) and marked with coloured arrows connecting core to rim or enclosed within dashed lines. The D5 clinopyroxene field is reported in green. Photomicrographs under parallel nicols are reported for some crystals (location of the analysed transects or points marked by red lines or dots, respectively); further photomicrographs are reported in Supporting Materials (Figure S1). Mineral abbreviations:


exhibited by these cargoes identifies "Stage A" cooling and crystallization during melt percolation at the pre-eruptive storage zone at the base of the MV crust, outlined in (b). Black lines enclose clinopyroxene compositions found at island-arc settings, recording growth in deep crustal mush environments: basic lavas from Stromboli [37] and Ruapehu [36]; exhumed island arc crustal section [35]. (b) Cross section of the multitiered magma plumbing system beneath Marsili Volcano, as in Figure 1c. Box "Stage A" marks location of deep crystallization events recorded by the D5, D4 and D1 clinopyroxene cargoes.
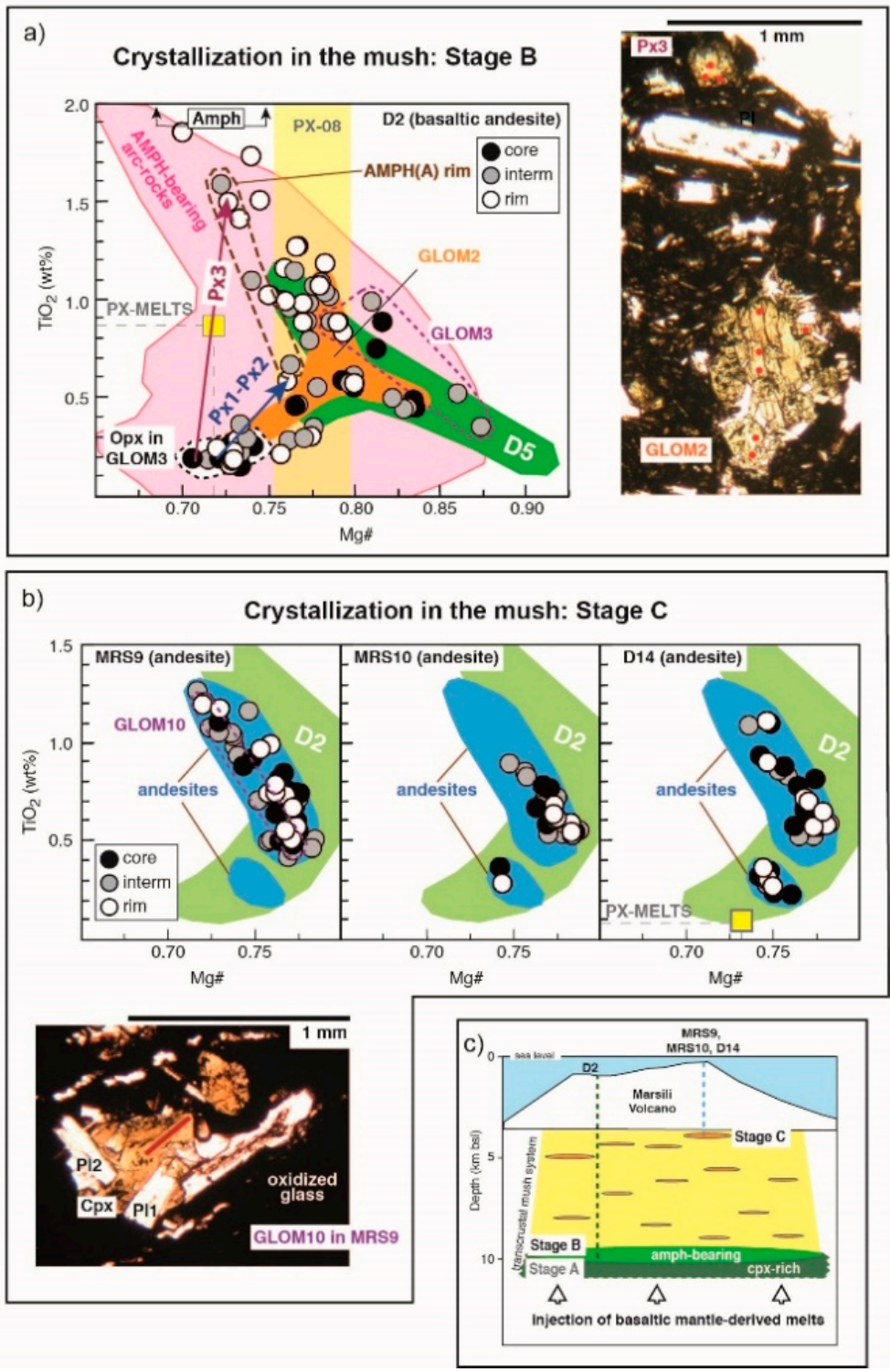

Figure 3. Clinopyroxene variability indicative of Stage B and Stage C crystallization. (a) $\mathrm{TiO}_{2}$ (wt $\%$ ) 
versus $\mathrm{Mg \#}$ for sample D2 clinopyroxene crystals. This cargo records Stage B events, storage zone reported in (c). The D2 clinopyroxene trend defines a continuum with the field of D5 clinopyroxenes (Stage A, green field) before splitting into two branches at the lowest Mg\# values (see GLOM2, orange field), pointing, respectively, to the compositional fields of orthopyroxene (low Ti, black dotted field) and amphibole (high Ti; Amph, black arrows) carried in the D2 lava [18]. The crystals are tagged as in Figure 2; further photomicrographs are reported in Supporting Materials (Figure S2). A similar $\mathrm{Mg \# - \textrm {TiO } _ { 2 }}$ relationship is shown by clinopyroxene cargoes from basic arc lavas (pink-coloured field), formed during cryptic amphibole crystallization in the crust $[32,40,41]$. (b) $\mathrm{TiO}_{2}$ (wt\%) versus $\mathrm{Mg \#}$ for the few pyroxene crystals carried in the MRS9, MRS10, D14 andesite lavas (light blue fields). These cargoes consist of orthopyroxene (Opx) and clinopyroxene (Cpx) crystals recording Stage C crystallization events, storage zone reported in (c). Note the large $\mathrm{TiO}_{2}$ range at the low $\mathrm{Mg \#}$ values of the clinopyroxene crystals, with some individual crystals (e.g., GLOM10 in MRS9 lava) covering this range, and the close match of andesite clinopyroxene compositions with the most differentiated end of the D2 clinopyroxenes (Stage B). Analytical error, yellow box and vertical band are displayed as in Figure 2. Other mineral abbreviations: Opx = orthopyroxene; Amph = amphibole. (c) Cross section of the multitiered magma plumbing system beneath Marsili Volcano, as in Figure 1c. Boxes "Stage B" and "Stage C" mark the location of the crystallization events recorded by the clinopyroxene cargoes of the D2 basaltic andesite and the andesite lavas, respectively.

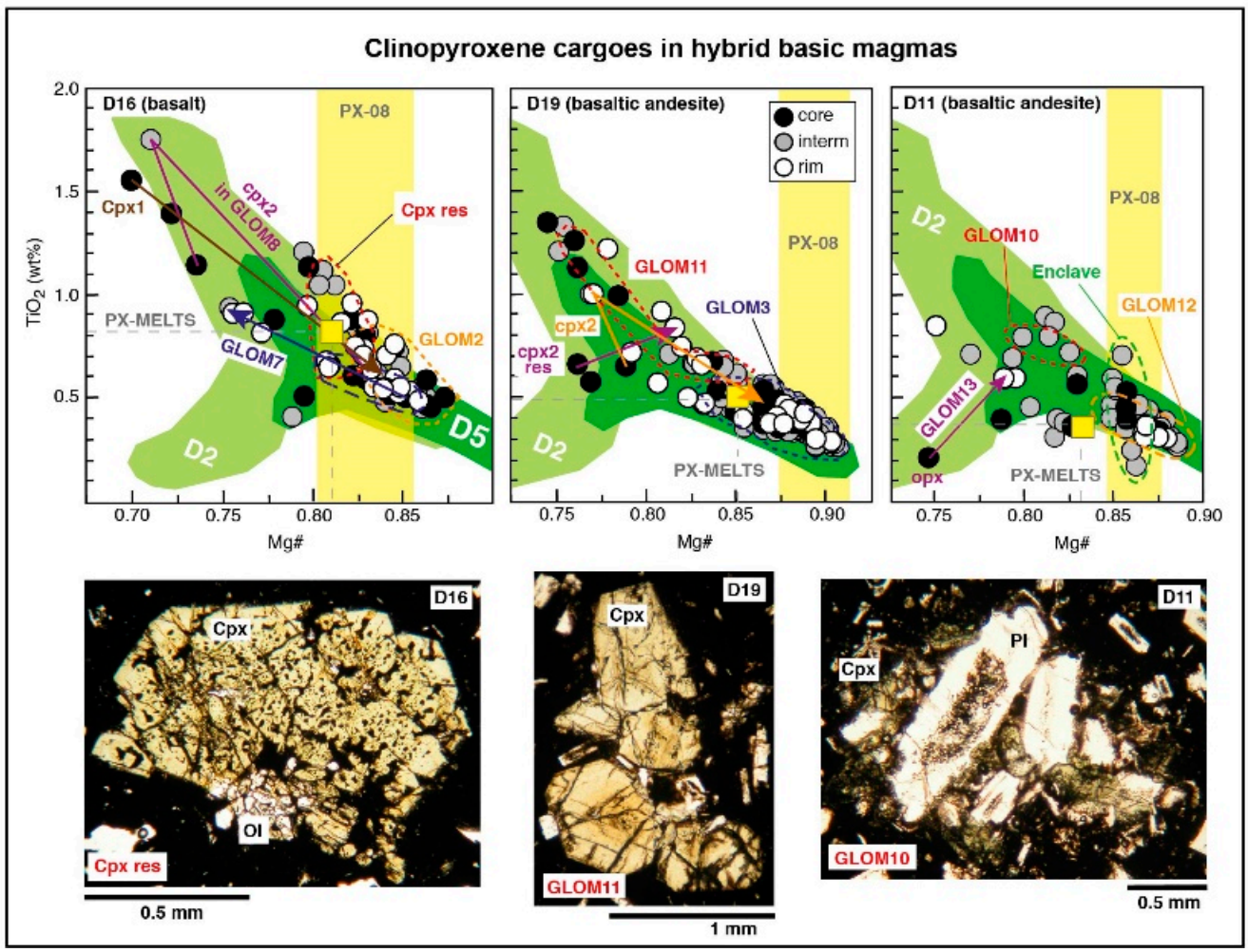

Figure 4. Plots of $\mathrm{TiO}_{2}(\mathrm{wt} \%$ ) versus $\mathrm{Mg} \#$ for the clinopyroxene cargoes in the D16 basalt and D11 and D19 basaltic andesites. These are hybrid basic lavas erupted at the MV south-eastern flank (Figure 1a). Note that these cargoes display a similar chemical variability, irrespective of the chemistry of the carrier lava, that covers most of the D5 and D2 fields. The crystals are tagged as in Figure 2; further photomicrographs are reported in Supporting Materials (Figures S3 and S4). Only in these lavas, partially resorbed clinopyroxene crystals (Cpx res) and gabbroic clots with open, sub-circular texture (Enclave) were found. Analytical error, yellow box and vertical band are displayed as in Figure 2. Light and dark green fields represent D2 and D5 clinopyroxenes, respectively, recording Stage A and Stage B crystallization in the deep MV mush. 
The Geosciences Editorial Office would like to apologize for any inconvenience caused to the authors and the readers by these changes. The changes do not affect the scientific results. The published version will be updated on the article webpage, with a reference to this Correction.

\section{Reference}

1. Trua, T.; Marani, M.P. Clinopyroxene Crystals in Basic Lavas of the Marsili Volcano Chronicle Early Magmatic Stages in a Back-Arc Transcrustal Mush System. Geosciences 2021, 11, 159. [CrossRef] 